\title{
Corpus
}

\section{Pluralismo religioso en una sociedad de pluralidad jerarquizada}

\section{Pablo Semán}

\section{(2) OpenEdition}

1 Journals

\section{Edición electrónica}

URL: http://journals.openedition.org/corpusarchivos/584

DOI: 10.4000/corpusarchivos.584

ISSN: 1853-8037

\section{Editor}

Diego Escolar

\section{Referencia electrónica}

Pablo Semán, «Pluralismo religioso en una sociedad de pluralidad jerarquizada », Corpus [En línea], Vol 3, No 2 | 2013, Publicado el 20 diciembre 2013, consultado el 19 abril 2019. URL : http:// journals.openedition.org/corpusarchivos/584; DOI : 10.4000/corpusarchivos.584

Este documento fue generado automáticamente el 19 abril 2019. 


\title{
Pluralismo religioso en una sociedad de pluralidad jerarquizada
}

\author{
Pablo Semán
}

\section{La "Argentina católica"}

1 La idea de una "Argentina católica" es tanto el producto de una situación histórico social que excede al campo académico como de situaciones específicamente relacionadas con los modos dominantes entre los especialistas en ciencias sociales.

2 En primer lugar, y más allá de su carácter de religión mayoritaria, es obvio que la pretensión hegemónica del catolicismo, así como el hecho de que durante tramos importantes de la historia nacional estuvo vinculado a las elites que impulsaron procesos políticos y sociales a nivel nacional, hacen al catolicismo un factor crucial de la vida política y social. Sin embargo eso que implicó, visto con alguna sobreestimación, la creación de una Nación Católica no es una realidad ni eterna ni homogénea . En parte porque ni "el catolicismo", ni "la nación" son o fueron entidades unificadas a lo largo del tiempo y el espacio social. $\mathrm{Y}$ en parte porque la pretensión hegemónica del catolicismo tiene que ser puesta en perspectiva para que no se evalúe la eventual hegemonía católica sin reponer en el análisis la contingencia que asiste a esa pretensión y los compromisos que se traban entre la mirada académica y esa pretensión (aún cuando esa mirada académica la rechace). Un ejemplo muy actual de este compromiso lo constituyen las actuales evaluaciones acerca del rumbo del papado por parte de analistas progresistas vinculados al catolicismo. Ellas naturalizan y magnifican el carácter católico de la sociedad argentina (o el carácter rector del Catolicismo en nuestra sociedad). Para ellos la cuestión de las libertades individuales en nuestro país parece estar estrictamente asociada al destino del catolicismo y por ello cualquier síntoma de inmovilismo papal en ese plano les parece una amenaza para la sociedad argentina. No negamos la influencia que pueda tener el catolicismo en ese plano, pero de ninguna manera eso conlleva aceptar el supuesto tácito de que lo que sucede con el catolicismo es lo que sucede con la 
Argentina. Con ese argumento ya hemos ingresado en la mirada académica y sobre ella es preciso decir algo más: si ella tiende a presuponer el compromiso "sociedad argentina catolicismo" no es solo porque como dijimos hasta acá refleje sin crítica, como si fuese un dato, las pretensiones de hegemonía del catolicismo.

Aún así y antes de enfrentar un condicionante más profundo de esta percepción, es necesario decir que cuando se afirma la "catolicidad de la argentinidad" se presupone mucho acerca de los dos términos. ¿Hasta dónde esa catolicidad es tan "católica", todo el tiempo? ¿Cuántas adaptaciones, conflictos y negociaciones supuso su establecimiento?. ¿Cuántos pactos de simulación, de aceptación y cuántas reinterpretaciones "desviantes", habitan símbolos que supuestamente son "puro catolicismo"? Pero también presuponen mucho acerca de la argentinidad: en cuanto a su propia homogeneidad y, también en cuanto a las dimensiones relevantes para el análisis. Así como se confunde el desarrollo del Catolicismo con el de las ideas dominantes entre parte de sus elites, sin siquiera referirse a cómo operan las estructuras parroquiales en el "catolicismo realmente existente", tampoco se dimensiona ni computa el grado en que la experiencia de la nación está mediada por factores que se dejan de lado porque son considerados de baja calidad cultural. Sólo para dar un ejemplo muy breve de lo que decimos: una parte de nuestras elites políticas y culturales de la actualidad elabora sus ideas y sentimientos sobre la nación a la luz de literatura masiva y no de las fuentes reverenciadas por las rutinas de investigación. Mientras la revista Contorno recibe los esfuerzos de decenas de jóvenes investigadores la literatura histórica masiva, víctima de su jerarquización social, recibe nulo interés a pesar de su enorme operatividad sociológica.

Pero en un nivel mucho más profundo, el planteo de la nación católica es posible porque formas muy corrientes de conceptualizar la relación entre sociedad y estado acompañan supuestos de la ontología católica. Buena parte de las grandes matrices sociológicas (en el sentido general de "ciencia social") en las que se montan las teorías de rango medio que analizan la religión, y muy especialmente aquellas matrices que son la base de la sociología del catolicismo, presuponen las nociones de la religión que pretenden analizar. Aquello que Carl Schmitt señala para el concepto de política y estado, se cumple también para la concepción de lo religioso en la sociología: la imagen metafísica del mundo que se forja una época determinada se traspone a la organización política que esa época tiene por evidente. La idea de una sociedad civil que, como communitas o asamblea, es recuperada, retraducida y representada por el estado, tiene más relación con las ideas católicas de lo que pensamos y es al mismo tiempo el supuesto y el fenómeno que se proponen establecer, medir y analizar los paradigmas dominantes. No sería justo ignorar que los paradigmas emergentes, o aquellos más inspirados en la experiencia de la sociedad norteamericana presuponen otra ontología (naturalizan, por ejemplo, el mercado y el individuo). Pero tampoco sería justo desconocer que la posición prevaleciente de los paradigmas referidos en primer término está en la base de la problematización de las relaciones entre religión y política que es el ámbito en donde suele verificarse la tesis de la argentina católica. Así, esa tesis no solo supone percepciones sesgadas y dispuestas por la hegemonía o por el entorno social sino, sobre todo, unos supuestos filosóficos que habitan la teoría sociológica que se pregunta por lo que en el fondo no deja de afirmar. 


\section{La posibilidad de visiones alternativas}

5 Las visiones alternativas a la descripta en primer término son, sobre todo, deseables. Surgen actualizando los "hechos científicos" y, por lo tanto las tomas de conciencia del "enmarcamiento" previo de las observaciones. Más aún: los discursos críticos de los enmarcamientos meta no terminan nunca de hacer sentido en la práctica de los investigadores sino es en el marco de investigaciones que obliguen a tornarlos disponibles para esa investigación. Sin embargo como las visiones catolicocéntricas de la sociedad y la religión están arraigadas tanto en los conceptos de la ciencia social como en las narrativas históricas, es necesario desarrollar un esfuerzo específico destinado a objetivar minuciosamente y desactivar esas categorías y sus vínculos.

En lo inmediato creo que es necesario efectuar un trabajo de compatibilización entre dos tendencias que percibo en los esfuerzos destinados a renovar la percepción de las ciencias sociales sobre la religión. Por un lado se hace un esfuerzo crítico de gran nivel de sutileza y rigor para superar las incrustaciones de catolicocentrismo y de todas las metafísicas que porta inconscientemente sedimentadas en la ciencia social. Así se avanza hacia la necesidad de percibir lo dinámico, lo relacional, lo heterogéneo en lo que conocemos como lo religioso y a lo que, esquematizando las cosas un poco, le atribuíamos estabilización, homogeneidad y una especie de carácter independiente de las relaciones y la historia. Por otro lado e independientemente de estos esfuerzos se encuentra la tendencia a enfocar un espectro más amplio de fenómenos de los que las ciencias sociales de la religión tomaban en cuenta así como a tomar nota de lo que en términos culturales podría subrayarse como una superación de la catolicidad de la Argentina. Sería interesante que hubiera un cruce sistemático entre nuevas perspectivas y viejos objetos: el catolicismo debe ser visto en diversos niveles y aspectos que habitualmente no se consideran: su transversalización por orientaciones religiosas "concurrentes", sus apropiaciones subalternas, y los pliegues que escapan tanto a la hegemonía como a las dinámicas puramente resistentes.

7 Muchos venimos haciendo un descubrimiento que en términos de trayectoria individual es muy interesante: que las definiciones de religión que poseemos al inicio de una investigación son desmentidas por nuestro objeto, lo que nos exige ampliar e incluso recentrar el concepto de lo religioso. Pero abandonarse exclusivamente a esa deriva nos hace dispensar problemáticas interesantes que se beneficiarían de las nuevas perspectivas aunque no totalmente purificadas. Por otro lado, si digo que es imposible es por algo muy específico: siempre se puede reconducir la definición de lo religioso a algo que no lo es. Pero eso no tiene sentido si al mismo tiempo no se asume que esa otra referencia a la que se conduce lo religioso es también culturalmente situada. La deconstrucción de lo religioso para reconducirlo a un nuevo principio presumiblemente claro y distinto es, en ese sentido, imposible.

\section{El estudio de la diversidad religiosa}

8 No hay una única manera de encarar productivamente el estudio de la diversidad religiosa, pero quiero referirme a una que me ha interesado especialmente en los últimos tiempos y es crecientemente vista como interesante por otros investigadores. Al parecer el agotamiento de las perspectivas institucionalistas de la religión, combinado con el 
hecho de que las "industrias culturales" movilizan significaciones y prácticas religiosas, se traduce en un interés por las relaciones entre "cultura" y "religión". Con las revisiones que deban imponerse a dichos conceptos (inclusive su "abolición") dicho cruce alberga el esfuerzo de investigadores que están atentos a tres hechos. En primer lugar el hecho de la diferencia entre identificaciones religiosas de los sujetos y las identidades colectivas que promueven los grupos o las identidades sociales que promueve la religión y que siempre decantan en hibridaciones "individuales". En segundo lugar el hecho de que ese aparente caos no se resuelve en términos de taxonomías negativas que refieren tanto a la "desinstitucionalización de la religión" como a la del estallido de la religiosidad en una infinitud de religiosidades electivas. Se resuelve en términos de redefiniciones de lo que entendemos por institución y de lógicas de formación de la sensibilidad religiosa que no solo abarcan combinaciones sino modos de tránsito. En tercer lugar el hecho de que el campo de las experiencias religiosas, que se define siempre en cruce con la cultura, no es un campo de "ideologías" sino de prácticas y experiencias que redefinen nociones de persona.

9 Estos tres hechos deben ser percibidos en su concomitancia y en su inclusión en un marco más general que debe conjugar, al menos, estas determinaciones. Veyne apuntaba a una cuestión decisiva en la vida social de las creencias: el creer implica la coexistencia de estatutos de verdad plurales y relativizables por los creyentes ${ }^{1}$. El creer por lo tanto implica universos de creencias que conviven sin estallar y sin ser llevadas hasta sus últimas consecuencias. Los programas de verdad que fundan la creencia son parte de un humus histórico que debe ser analizado en cada caso para remitir a ese campo de probabilidades la experiencia constitutivamente plural y contradictoria de la creencia. Las creencias suelen ser un objeto escurridizo y mal planteado. Se las indaga esperando encontrar aceptaciones que se cumplen literalmente (incluso de forma fanática), y se encuentra, las más de las veces, creyentes que se describen como "astutos", "incompetentes" o "inconsecuentes" o "liberales" porque que "nunca cumplen" hasta las últimas consecuencias o "mezclan". A partir de esas definiciones las creencias se ofrecen más a un juicio normativo implícito que a un análisis sociológico: los creyentes son poco o demasiado ortodoxos. La sociología se reduce a una suspicacia sobre prácticas creyentes que naufragan entre la denuncia y la postulación de decadencias correlativas al estallido del mundo en trillones de mónadas.

Esa misma crítica exige entender la pluralidad de formas del creer a la luz de su unidad conceptual y su posición específica en lo social. Aquí la referencia es Michel De Certeau. Desde su punto de vista, que también admitía la variabilidad y la "inconsistencia de la creencia" el creer es anterior a su expresión en el campo religioso. Es co-extensivo a la sociabilidad como una práctica de la diferencia (tanto en sentido temporal como "interpersonal"). El creyente actúa, ofrenda, comunica en nombre de unas tradiciones que lo habilitan a confiar que ese acto desencadenará devolución e implica, una espera (primer sentido de la diferencia, temporal) de un otro (segundo sentido, interpersonal, de la diferencia), que actualiza esa expectativa o no. El creer implica creyentes e instituciones $\mathrm{y}$, sobre todo, tradiciones que se invocan en el cruce de múltiples trayectorias subjetivas, múltiples tradiciones y múltiples creencias. El creer es comunicación con todas las incertidumbres que le asisten al comunicar e insanablemente procesual, en un desplazamiento sin fin. Así, la definición de De Certeau es consistente con la de Veyne: la pluralidad contradictoria del creer en el segundo, es el resultado del mecanismo histórico social del creer según el primero. 
11 La historia, desde ese punto de vista, es comunicación creada y recreada. Es, justamente, en la combinación de las perspectivas de Veyne y De Certeau que hallamos una comprensión que permite pensar relacionalmente el creer como un juego de múltiples comunicaciones cruzadas en las que la creencia no tiene nunca las medidas de la simulación o el fanatismo y en las que las realidades creyentes subvierten la estereotipación. Esto no implica renunciar a la conceptualización o rendirse a la infinitud del mundo sino entender que la unidad de análisis del creer es el proceso y las creencias, los creyentes y las instituciones son momento.

El reenvío de lo religioso a su plano de emergencia en el punto de cruce entre lo social y lo cultural (y todo lo de político que tienen esas dimensiones) puede comprenderse con el giro que propuso Pierre Bourdieu en torno a su propia obra. Entre todas las sugestiones críticas que se han realizado sobre la noción de campo religioso es la del propio Bourdieu la que plantea la necesidad de advertir que los conceptos de nivel más abstracto estaban contaminados de la historicidad francesa-y europea en general-, e incluso de la mirada que ciertos actores de esa sociedad podían tener sobre el campo religioso. Así en "La disolución de lo religioso" (1985, p.103), afirmaba que parte de las definiciones que inspiraban el análisis de su texto de 1971 -"Génesis y estructura del campo religioso"eran definiciones "inconscientemente universalizadas", pero no eran "aptas sino para un estado histórico del campo".

Esto implica entender que la definición de los bienes del campo religioso como de "salvación", y su disputa, como la del monopolio de la oferta legítima de los mismos, es definir las cosas con demasiado centramiento en las definiciones institucionalizadas de la religión por el catolicismo y el protestantismo. Así Bourdieu admitía de una manera pionera respecto de sus propios críticos, que los usos más frecuentes del concepto de campo religioso, el hecho de que la diversidad cultural y temporal de una sociedad, hace de los campos religiosos dominios mucho mas variables, imprecisos y heterogéneos que los que se presupone (y de lo que obligaba pensar su texto de 1971). Cambian los conceptos para percibir los hechos de hoy y de siempre. En el campo religioso heterogeneizado -tanto en la historia como en los conceptos-, lejos de ocurrir lo que describe Bourdieu en 1971 -que además no necesariamente ocurre, siquiera, en 1971-, no compiten tan sólo distintas fórmulas para comprender la eucaristía o administrar la salvación. En él se confrontan concepciones que tienen como bien religioso a la salvación, pero también la sanidad, la prosperidad, etc. En el campo religioso heterogeneizado, y no solo contemporáneamente, compiten el consuelo de la cruz, la promesa de sanación, las búsquedas interiores a través de la dieta y los ejercicios respiratorios. El campo religioso es un campo de disputa en el que se apuntalan, expresan y refuerzan no solo definiciones de la religión sino, nociones de persona y alteración de las que las "religiones" son un elemento co-participante.

Esta situación de disputa de lo que es o no es religión también nos hace ver dos vectores complementarios. El hecho de que el campo religioso sea pluralista por definición, porque, en el límite toda religión se reproduce diversificándose de versión en versión no es incompatible con el hecho de que esta sea vista como un campo de fuerzas, de relaciones de fuerza, más específicamente. Y este último hecho, que en Argentina ha implicado una presencia dominante del catolicismo no debe confundirse con una posibilidad mítica: la de un dominio que no sea una relación de fuerzas y por ende no haya estado afectada, desde su inicio, por el trabajo "erosivo" de las más diversas fuerzas subordinadas (pero no "muertas"). 


\section{Los "otros" religiosos} pesado una visión que es la confluencia de los a priori de un catolicismo secularizado e iluminismo. Desde esa posición surge una presión para un diseño de la disciplina escindida en dos planos: la "normalidad religiosa", considerada como ideología, y tenida en cuenta en sus relaciones con la política y las "anormalidades" consideradas a partir de sus signos exteriores de "misticismo" y rareza tomadas como peligro o cambio. La reflexión que promueve este cuestionario alienta la superación de este punto de partida.

En la vida social la Santa Alianza de catolicismo e iluminismo es una fuerza que compite con núcleos de "integrismo", y con la emergencia de puntos de vista pos-secularizados que rehabilitan la religión y su redefinición en el espacio público así como nuevas espiritualidades. Lo que se señala como alteridad es así el resultado de posiciones diferentes y móviles en un contexto que debería considerarse como de pluralismo jerarquizado. Vivimos en una sociedad con pluralidad, pero no hay necesariamente una lectura pluralista de esa pluralidad.

\section{BIBLIOGRAFÍA}

Bourdieu, P. (1986). La disolución de lo religioso. En Cosas dichas (pp. 104). Buenos Aires: Gedisa.

Bourdieu, P. (1971). Genèse et structure du champ religieux. Revue Française de Sociologie, 12(3), 295-334.

Veyne, Paul (1983). Les Grecs ont-ils cru à leurs mythes? Essai sur l'imagination constituante. Paris: Editions du Seuil.

\section{NOTAS}

1. "Comment peut-on croire à moitié ou croire à des choses contradictoires ? Les enfants croient à la fois que le Père Noël leur apporte des jouets par la cheminée et que ces jouets y sont placés par leurs parents: alors, croient-ils vraiment au Père Noël? Oui, et la foi des Dorzé n'est pas moins entière ; aux yeux des Éthiopiens, nous dit Dan Sperber, "le léopard est un animal chrétien, qui respecte les jeûnes de l'Église copte, observance qui, en Éthiopie, est le test principal de la religion ; un Dorzé n'en est pas pour autant moins soucieux de protéger son bétail le mercredi et le vendredi, jour de jeûne, et qu'ils mangent tous les jours ; les léopards sont dangereux tous les jours : il le sait d'expérience ; Ils sont chrétiens : la tradition le lui garantit" (Veyne, 1983). 


\section{AUTOR}

\section{PABLO SEMÁN}

CONICET (Consejo Nacional de Investigaciones Científicas y Técnicas)- IDAES, Universidad Nacional de San Martín, Argentina.

Correo electrónico: pabloseman@hotmail.com 